\title{
Prevalence of Adult Attention Deficit Hyperactivity Disorder (ADHD) among Undergraduates at BUITEMS
}

\section{Nida Tabassum Khan* and Khadija Khan}

Department of Biotechnology, Faculty of Life Sciences and Informatics, Balochistan University of Information Technology Engineering and Management Sciences, Quetta, Pakistan

\begin{abstract}
Adult attention deficit hyperactivity disorder (ADHD) is a psychosomatic issue which comprises of complications like problem in paying attention, hyperactivity and impulsive behavior. Our obtained results indicated that the general incidence rate of attention deficit hyperactivity disorder in adult population is low that out of 100 undergraduates $36 \%$ were ADHD, $53 \%$ were non-ADHD and $11 \%$ were possible ADHD. Besides it was also revealed from this study that attention deficit hyperactivity disorder is widespread in adult males than in females this is probably due to the constricting emotional nature of males' influenced by the perceived stereotypic virility. However it is crucial to identify $A D H D$ as a serious mental health issue in adults for early treatment and personality management.
\end{abstract}

Keywords: Adult attention deficit hyperactivity disorder; Impulsivity; Inattention hyperactivity; Wender utah rating scale

\section{Introduction}

Attention deficit hyperactivity disorder (ADHD) is a described as a neurobehavioral syndrome which affects approximately 5 to $10 \%$ of children or juveniles and $3 \%$ of adults [1]. It is reported that the average age for ADHD diagnosis is seven [2]. In the beginning it was known by many names for example, organic driveness, hyperkinetic impulse disorder, hyperactivity, nominal brain dysfunction and attention deficit condition [3,4]. Until in 1960s the American Psychiatric Association (APA) formally documented ADHD as a mental illness [5]. ADHD became distinguishable as a mental issue in 1902 and described as an abnormal illness of moral control in children [6]. Children with ADHD could not control their behavior as normal child could however, they were nevertheless sensible and intelligent [7]. ADHD is identified almost three times more frequently in males than in females [8]. Around 30 to $50 \%$ of children with ADHD have indications in adulthood [9]. It is a psychosomatic issue that includes tenacious complications like problem in paying attention, hyperactivity and impulsive behavior [10]. Thus ADHA is persistent neurobehavioral problem which could include an individual's capacity to inhibit conduct (impulsivity), characteristic effectivity in goal-oriented undertakings (inattention), or alter the activity stage (hyperactivity) in developmentally appropriate ways $[11,12]$. ADHD indications are not constant. Different individuals experience ADHD symptoms contrarily and to erratic degree of severity $[13,14]$. Overall incident of ADHD is estimated to be from $3 \%$ to $7 \%$ beginning from school age [15]. However frequency of ADHD in Pakistan has been reported to be around 2.49\%. Ratios vary significantly from 2:1 to 9:1 [16]. Factually, it was assumed that ADHD was outgrown in mid to late puberty requiring treatment throughout their lives $[17,18]$. Adult attention deficit hyperactivity disorder (ADHD) can be cause of precarious relationship, poor work or school performance, low self-esteem, and so on [19]. It makes it difficult for person to pay attention but also control their impulsive behavior [20]. Although symptoms of ADHD begins in childhood but can continue through adolescence and adulthood [21]. It is seen in adulthood because the disorder has been undiagnosed as a child and if the disorder is not diagnosed or discovered it can led to number of difficulties which may be social, academic and occupational trouble along with the symptoms of inattention or impulsiveness [22,23]. Since very scarce data is available on ADHD in adults in Pakistan.
Hence the purpose of this study was to determine the prevalence of ADHD among adult undergraduates studying at BUITEMS.

\section{Materials and Methods}

Random selection of undergraduate students from different departments studying at BUITEMS, Quetta, Pakistan keeping the sample size as 100. Diagnostic assessment of ADHD was done with the aid of a clinically acknowledged scale known as Wender Utah Rating Scale (WURS) [24]. Wender Utah Rating Scale items were rated using a 5-point Likert scale whereby $0=$ not at all or very slightly and $4=$ very much. Adult individuals with score $\leq 46$ were classified as non- ADHD, score $\geq 56$ as ADHD. Statistical assessment of the data was done using Microsoft excel.

\section{Results}

Figure 1 shows the sex distribution of the sample. Out of 100 undergraduate, $53 \%$ were females while $47 \%$ were males as shown in Figure 1. Figure 2 reveals the correlation between adult attention deficit hyperactivity disorder and its three dimensions in both the genders. Figure 3 reveals the gender wise incidence of adult attention deficit hyperactivity disorder and Figure 4 reveals the overall occurrence of ADHD.

\section{Discussion}

Our study revealed that the overall incidence of Adult attention deficit hyperactivity disorder (ADHD) is low among the studied participants. Figure 4 suggested that out of 100 participants $36 \%$ were ADHD, 53\% were non-ADHD and $11 \%$ were on the border line that they might have ADHD keeping in mind that our sample consisted

*Corresponding author: Nida Tabassum Khan, Department of Biotechnology, Faculty of Life Sciences and Informatics, Balochistan University of Information Technology and Management Sciences, Pakistan, E-mail: nidatabassumkhan@yahoo.com

Received September 26, 2018; Accepted October 01, 2018; Published October 07, 2018

Citation: Khan NT, Khan K (2018) Prevalence of Adult Attention Deficit Hyperactivity Disorder (ADHD) among Undergraduates at BUITEMS. J Biomol Res Ther 7: 165. doi:10.4172/2167-7956.1000165

Copyright: $\odot 2018$ Khan NT, et al. This is an open-access article distributed under the terms of the Creative Commons Attribution License, which permits unrestricted use, distribution, and reproduction in any medium, provided the original author and source are credited. 
Citation: Khan NT, Khan K (2018) Prevalence of Adult Attention Deficit Hyperactivity Disorder (ADHD) among Undergraduates at BUITEMS. J Biomol Res Ther 7: 165. doi:10.4172/2167-7956.1000165

Page 2 of 3

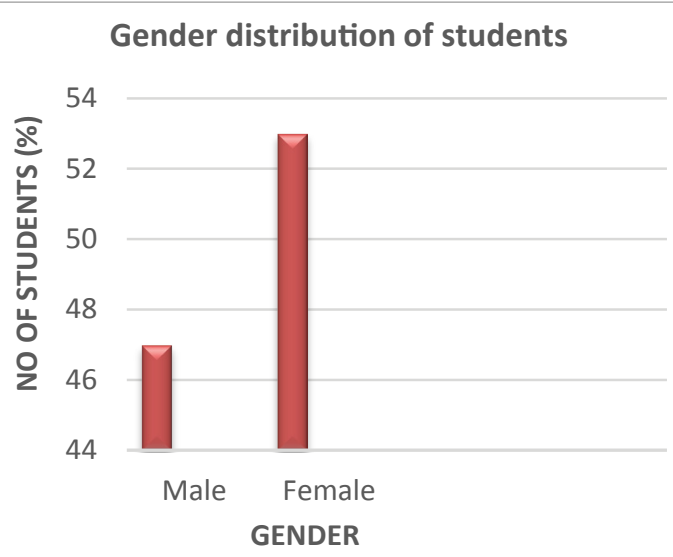

Figure 1: Gender distribution of selected students.

\section{Correlation between ADHD and its factors}

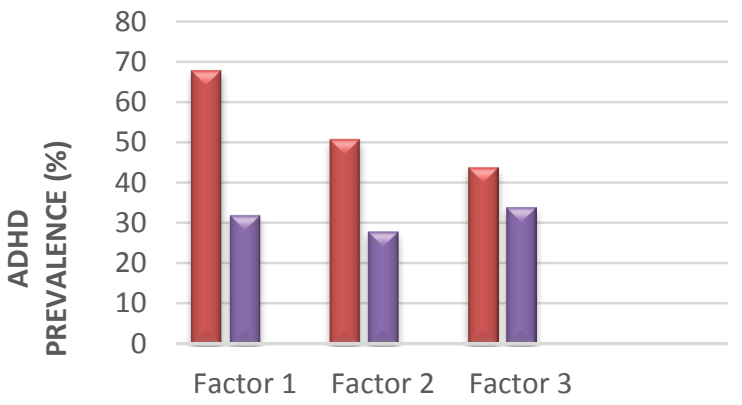

ADHD ASSOCIATED FACTORS

$\square$ Males $\square$ Females

Figure 2: Correlation between ADHD and its three dimensions in both the gender.

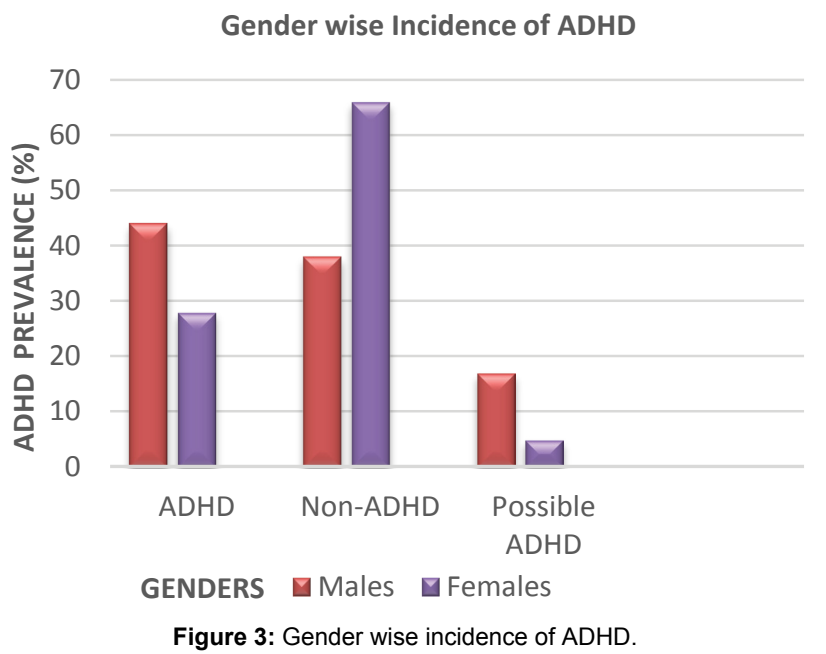

of $47 \%$ males and 53\% females as indicated in Figure 1. Our results revealed that Adult attention deficit hyperactivity disorder is more common in males than in females as indicated in Figure 3 that $44 \%$ of males had ADHD while only $28 \%$ females were reported ADHD. Therefore our obtained result supported the fact that the prevalence

\section{Overall Incidence of ADHD}

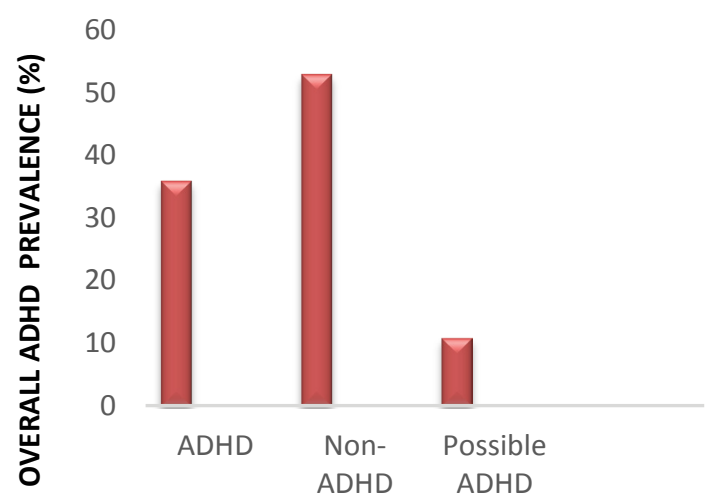

Figure 4: Over all incidence of ADHD.

of adult attention deficit hyperactivity disorder (ADHD) is much higher among males than in females. High prevalence of adult attention deficit hyperactivity disorder (ADHD) in males is probably due to the constricting emotional nature of males' influenced by the perceived stereotypic virility $[25,26]$. These men had been dejected as young fellows from imparting and examining their sentiments by gatekeepers, companions, instructors, or recreations coaches, and some were even repelled for doing thusly [27]. Along these lines, they didn't improve a terms for, nor an attentiveness of, countless feelings [28]. One standardizing manly part prerequisite is the limitation of enthusiastic articulation [29]. This standard is conjectured to set up and keep up control and to conceal weakness in a male centric social framework [30]. So we can say that there is a correlation between the authentication of customary maleness ideology and adult attention deficit hyperactivity disorder. Aspect of socialization undertakes a part in the progression of restrained emotionality suggesting that men are mainly less sensitive and fervent but rather more sensible than women $[31,32]$. Additionally the nervous system of males and females work differently in terms of critical thinking and emotional functioning, therefore ADHD effects males and females differently $[33,34]$

\section{Conclusion}

Thus in the light of this research study it is therefore concluded that Adult attention deficit hyperactivity disorder (ADHD) is more prevalent in males and is associated with numerous functional and emotional problems. Therefore it is imperative to report this problem at university level because it might have disturbing effects on adult.

\section{References}

1. Dalsgaard S (2013) Attention-deficit/hyperactivity disorder (ADHD). European Child \& Adolescent Psychiatry 22: 43-48.

2. Frank-Briggs Al (2011) Attention deficit hyperactivity disorder (ADHD). J Pediatr Neuro 9: 291-298.

3. Biederman J (1991) Attention deficit hyperactivity disorder (ADHD). Annals of Clinical Psychiatry 3: 9-22.

4. Voeller KK (2004) Attention-deficit hyperactivity disorder (ADHD). J Child Neuro 19: 798-814.

5. Barkley RA, Murphy KR (1998) Attention-deficit hyperactivity disorder: A clinical workbook. Guilford Press.

6. American Academy of Pediatrics (2001) Clinical practice guideline: treatment of the school-aged child with attention-deficit/hyperactivity disorder. Pediatrics 108: 1033. 
Citation: Khan NT, Khan K (2018) Prevalence of Adult Attention Deficit Hyperactivity Disorder (ADHD) among Undergraduates at BUITEMS. J Biomol Res Ther 7: 165. doi:10.4172/2167-7956.1000165

Page 3 of 3

7. Murphy K, Barkley RA (1996) Attention deficit hyperactivity disorder adults: comorbidities and adaptive impairments. Comprehensive psychiatry 37: 393401.

8. Biederman J, Faraone SV, Spencer T, Wilens T, Norman D, et al. (1993) Patterns of psychiatric comorbidity, cognition, and psychosocial functioning in adults with attention deficit hyperactivity disorder. American J Psychiatry 150: 1792-1798.

9. Brown RT, Du Paul G, Earls M, Feldman HM, Ganiats TG, et al. (2011) ADHD: clinical practice guideline for the diagnosis, evaluation and treatment of attention-deficit/hyperactivity disorder in children and adolescents. Pediatrics 128: 1007-1022.

10. Barkley RA, Edwards G, Laneri M, Fletcher K, Metevia L, et al. (2001) Executive functioning, temporal discounting, and sense of time in adolescents with attention deficit hyperactivity disorder (ADHD) and oppositional defiant disorder (ODD). J Abnormal Child Psychol 29: 541-556.

11. Biederman J, Newcorn J, Sprich S (1991) Comorbidity of Attention deficit hyperactivity disorder. Am J Psychiatry 148: 564-577.

12. Biederman J, Spencer T (1999) Attention-deficit/hyperactivity disorder (ADHD) as a noradrenergic disorder. Biolog Psychiatry 46: 1234-1242.

13. Mental health in the United States. Prevalence of diagnosis and medication treatment for attention-deficit/hyperactivity disorder- United States 2003 MMWR. Morbidity and Mortality Weekly Report 294: 2293-2296.

14. Barkley RA (1997) Attention-deficit/hyperactivity disorder, self-regulation and time: towards a more comprehensive theory. J developmental and Behavioral Pediatrics.

15. Rowland AS, Lesesne CA, Abramowitz AJ (2002) The epidemiology of attention $\square$ deficit/hyperactivity disorder (ADHD): a public health view. Mental Retardation and Developmental Disabilities Research Reviews 8: 162-170.

16. Biederman J (2005) Attention-deficit/hyperactivity disorder: a selective overview. Biological Psychiatry 57: 1215-1220.

17. Barkley RA (2002) Major life activity and health outcomes associated with attention-deficit/hyperactivity disorder. J Clin Psychiatry 63: 10-15.

18. Biederman J (1998) Attention-deficit/hyperactivity disorder: A life-span perspective. The J Clin Psychiatry 59: 4-16.

19. Biederman J, Monuteaux MC, Doyle AE, Seidman LJ, Wilens TE, et al. (2004) Impact of executive function deficits and attention-deficit/hyperactivity disorder $(\mathrm{ADHD})$ on academic outcomes in children. J Consult and Clin Psychology 72: 757.

20. Kutcher S, Aman M, Brooks SJ, Buitelaar J, Van Daalen E, et al. (2004) International consensus statement on attention-deficit/hyperactivity disorder $(\mathrm{ADHD})$ and disruptive behaviour disorders (DBDs): clinical implications and treatment practice suggestions. European Neuropsychopharmacology 14: 11-28.

21. De Graaf R, Kessler RC, Fayyad J, ten Have M, Alonso J, et al. (2008) The prevalence and effects of adult attention-deficit/hyperactivity disorder (ADHD) on the performance of workers: results from the WHO World Mental Health Survey Initiative. Occup Environ Med 65: 835-842.

22. Simon V, Czobor P, Bálint S, Mészáros A, Bitter I, et al. (2009) Prevalence and correlates of adult attention-deficit hyperactivity disorder: meta-analysis. British J Psychiatry 194: 204-211.

23. Horner BR, Scheibe KE (1997) Prevalence and implications of attention-deficit hyperactivity disorder among adolescents in treatment for substance abuse. $J$ Am Acad of Child \& Adolescent Psychiatry 36: 30-36

24. Ward MF (1993) The Wender Utah Rating Scale: an aid in the retrospective. Am J Psychiatry 150: 885-890.

25. Lisak D, Hopper J, Song P (1996) Factors in the cycle of violence: Gender rigidity and emotional constriction. J Traumatic Stress 9: 721-743.

26. Vaillant GE (1974) Natural history of male psychological health II. Some antecedents of healthy adult adjustment. Archives of General Psychiatry 31 $15-22$.

27. Kring AM, Smith DA, Neale JM (1994) Individual differences in dispositional expressiveness: development and validation of the Emotional Expressivity Scale. J Personality and Social Psychol 66: 934

28. Phillips DA (2006) Masculinity, male development, gender, and identity: Modern and postmodern meanings. Issues in Mental Health Nursing, 27: 403-423.

29. Soumendra S, Srilekha S, Asyraf BR (2013) Corroborative psychobiologica indices explaining young adolescent emotionality. Procedia-Social and Behavioral Sci 91: 614-623.

30. Levant RF, Good GE, Cook SW, O'neil JM, Smalley KB, et al. (2006) The normative Male Alexithymia Scale: Measurement of a gender-linked syndrome. Psychology of Men \& Masculinity 7: 212

31. Watkins $C D$, Jones BC, DeBruine $L$ (2010) Individual differences in dominance perception: Dominant men are less sensitive to facial cues of male dominance. Personality and Individual Differences 49: 967-971.

32. Brody LR, Hall JA (2008) Gender and emotion in context. Handbook of emotions 3: 395-408.

33. Koch K, Pauly K, Kellermann T, Seiferth NY, Reske M, et al. (2007) Gender differences in the cognitive control of emotion: An fMRI study. Neuropsychologia 45: $2744-2754$.

34. Bell EC, Willson MC, Wilman AH, Dave S, Silverstone PH (2006) Males and females differ in brain activation during cognitive tasks. Neuroimage 30: 529 538. 